\title{
Piezoelectric properties, hysteresis behaviour and dielectric properties of PMN-PZT ceramics
}

\author{
K V S RAMAM, K V R MURTHY, K TRINATH* and \\ A BHANUMATHI \\ Solid State Physics Laboratories, Andhra University, Visakhapatnam 530003, India \\ * Naval Science and Technological Laboratory, Visakhapatnam 530027, India \\ MS received 2 June 1995
}

Abstract. Ferroelectric and piezoelectric properties of $x \mathrm{~Pb}\left(\mathrm{Mg}_{1 / 3} \mathrm{Nb}_{2 / 3}\right) \mathrm{O}_{3}-(1-x) \mathrm{Pb}$ $\left(\mathrm{Zr}_{0.55} \mathrm{Ti}_{0.45}\right) \mathrm{O}_{3}$ system have been investigated. $\mathrm{X}$-ray diffraction patterns indicate rhombohedral and cubic structures. Maximum dielectric constant and piezoelectric properties are exhibited by 0.5-0.5 PMN-PZT composition. $P$ is high in 0.6-0.4 PMN-PZT composition.

Keywords. Piezoelectricity; PMN; dielectric constant.

\section{Introduction}

This paper highlights the structure, hysteresis behaviour and piezoelectric properties of $\mathrm{Pb}\left(\mathrm{Mg}_{1 / 3} \mathrm{Nb}_{2 / 3}\right) \mathrm{O}_{3}-\mathrm{Pb}\left(\mathrm{Zr}_{0.55} \mathrm{Ti}_{0.45}\right) \mathrm{O}_{3}$ composition and the effect of lanthanum doping on selected compositions. Previous work on PMN-PZT (Ouchi et al 1965) has shown that the system exhibits high values of dielectric constant and planar coupling coefficient at morphotropic phase boundary. Hysteresis behaviour and $d_{33}$ measurements have not been reported for this potentially important system. In this work we used the columbite precursor method (Swartz and Shrout 1982) to eliminate the pyrochlore structure. The dielectric, piezoelectric and hysteresis behaviour of $x \mathrm{~Pb}\left(\mathrm{Mg}_{1 / 3} \mathrm{Nb}_{2 / 3}\right) \mathrm{O}_{3}-(1-x) \mathrm{Pb}\left(\mathrm{Zr}_{0.55} \mathrm{Ti}_{0.45}\right) \mathrm{O}_{3}$ for $x=0.4,0.5,0.6,0.7$ and 0.8 are reported.

\section{Experimental}

The ceramics were prepared by conventional sintering of relevant oxides. To avoid pyrochlore phase formation, columbite precursor of $\mathrm{MgNb}_{2} \mathrm{O}_{3}$ was prepared first and then mixed with $\mathrm{PbO}$ to prepare $\mathrm{PMN}$. The calcination and sintering temperatures for preparing PMN-PZT ceramics were $950^{\circ} \mathrm{C}$ for $3 \mathrm{~h}$ and $1225-1250^{\circ} \mathrm{C}$ for $4 \mathrm{~h}$, respectively. For piezoelectric measurements and hysteresis behaviour the sintered pellets were poled by applying a d.c. electric field of $20 \mathrm{kV} / \mathrm{cm}$ for $1 \mathrm{~h}$ at elevated temperatures in silicon oil. The samples were cooled to room temperature for $1 \mathrm{~h}$ with field maintained.

Powder X-ray diffraction studies were carried out on Philips X-ray diffractometer (PW-1710) using $\mathrm{CuK}_{\alpha}$ radiation with $\mathrm{Ni}$ filter at room temperature. The diffraction patterns were recorded at a slow scan of $1 \%$ min.

Dielectric constant and dissipation factor were measured with Hewlett-Packard LF impedance analyser model $1492 \mathrm{~A}$. Planar and thickness coupling coefficients were also investigated using the same instrument. The coefficient $d_{33}$ is measured on Berlincourt $d_{33}$ meter. For the observation of hysteresis loops modified Sawyer and Tower circuit (Sinha 1965) was used. 


\section{Results and discussion}

All the compositions lie in the pseudocubic region of PMN-PZT phase diagram (Ouchi et al 1965). X-ray diffraction patterns of calcined powders are shown in figure 1. Pyrochloro phase remained in the calcined powders as shown in figure 1. In sintered powders, pyrochloro phase is absent. But to emphasize the effect of lanthanum doping X-ray patterns of calcined powders àre only shown. 0.5-0.5 PMN-PZT exhibits rhombohedral structure. Lanthanum doping leads to strong cubic character as is evident from the intensities of labelled peaks which match those of cubic PMN(JCPDS 27-1119). La doping leads to ordering of the structure. Same conclusion was reached in a previous work on lanthanum doped PMN-PZT (Kim et al 1989). Pyrochlore phase decreases with lanthanum doping. In 0.6-0.4 PMN-PZT which is rhombohedral, lanthanum doping leads to decrease in intensity of 100,111,200 and 211 lines. In 0.7-0.3 lanthanum doping causes decrease of intensity of 211 line. Smaller peaks may correspond to scattering effects of interstitial ions or diffusion of larger amount of ions into grain. Pyrochloro phase is maximum in 0.8-0.2 PMN-PZT as PMN content is maximum.

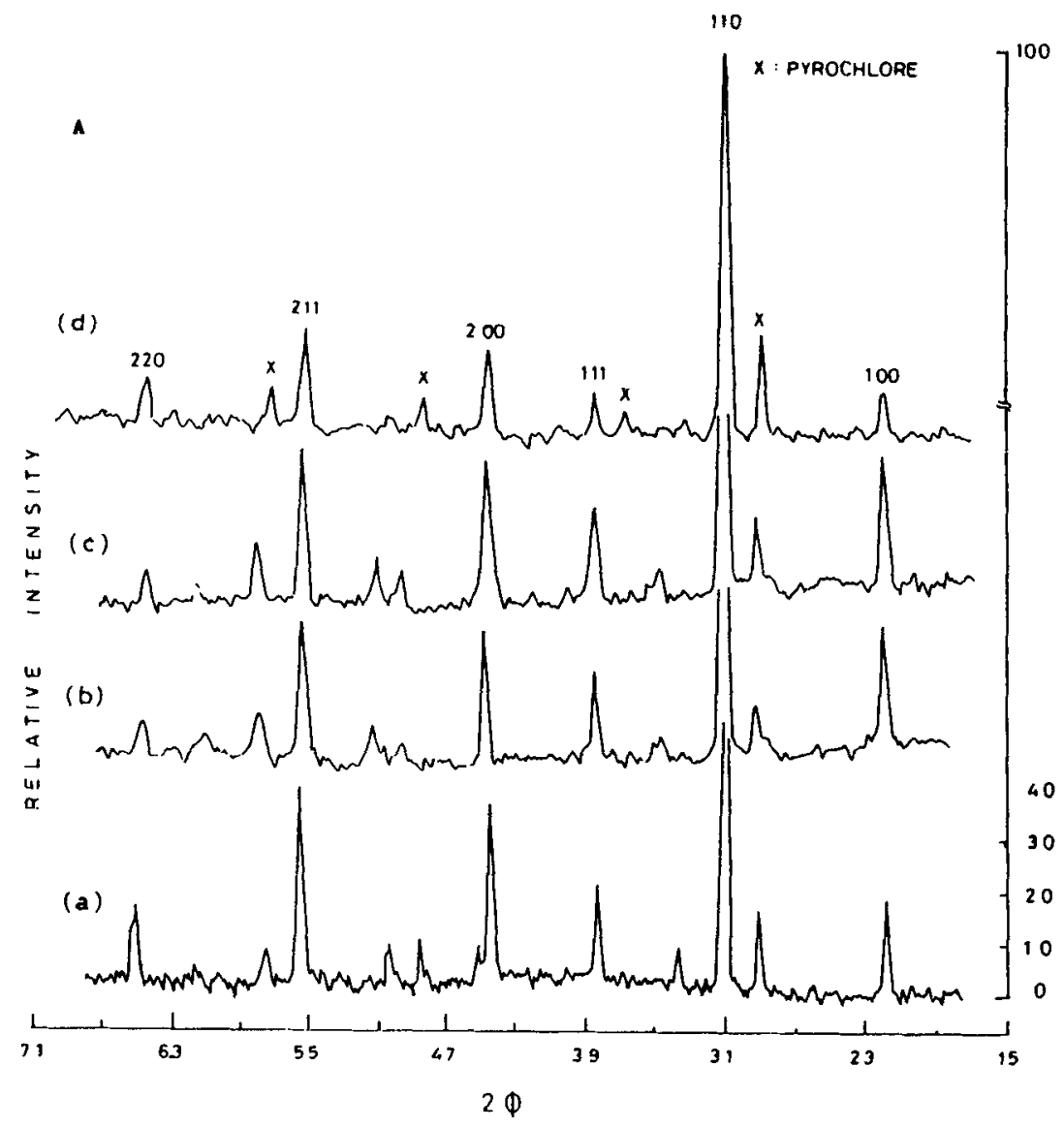

Figure 1. A. 


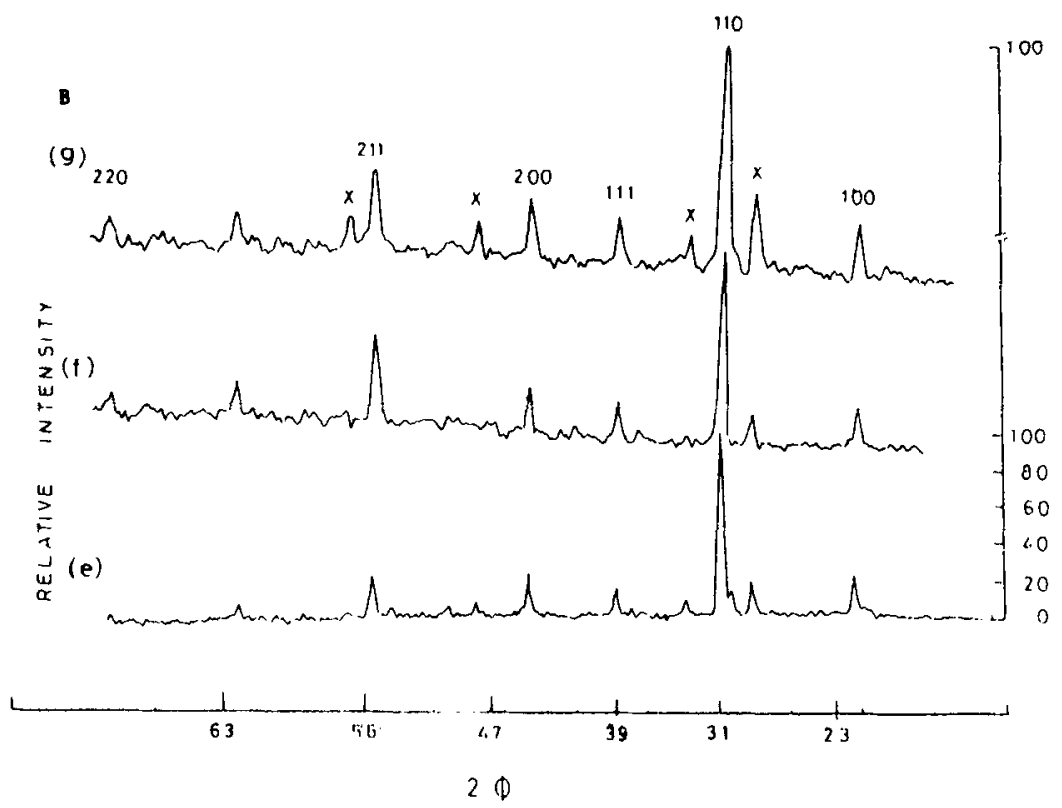

Figure 1. A. X-ray diffraction patterns of (a) 0.5-0.5, (b) 0.5-0.5 (La), (c) 0.6-0.4 and (d) 0.6-0.4 (La) PMN-PZT compositions and B. X-ray diffraction patterns of (e) 0.7-0.3 (La), (f) 0.7-0.3 and (g) 0.8-0.2 PMN-PZT compositions.

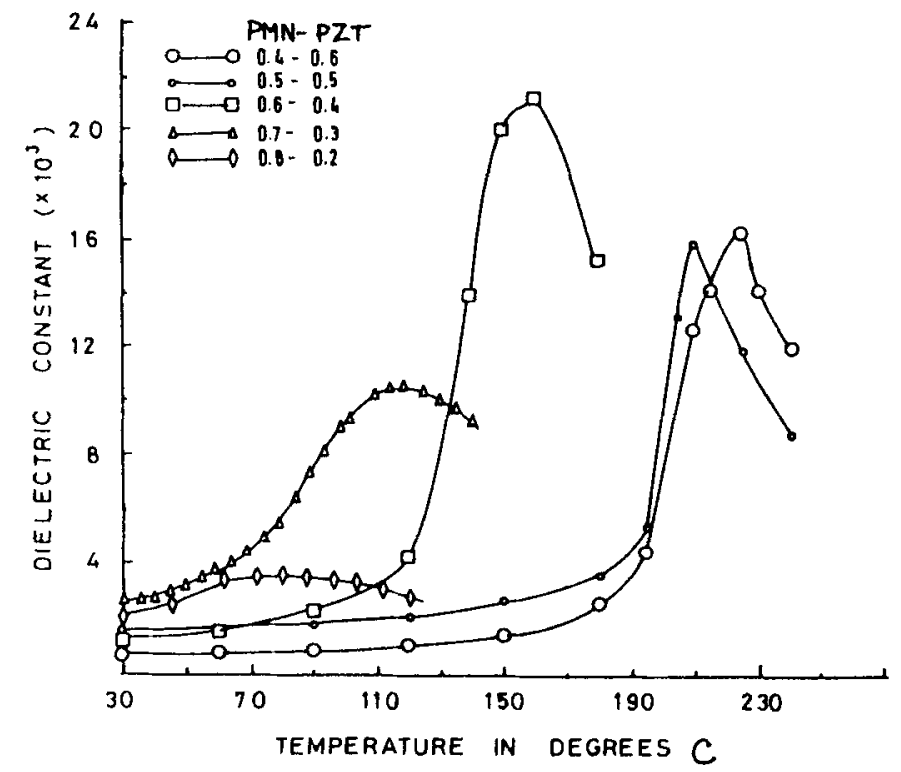

Figure 2. Dielectric constant variation with temperature.

Variation of dielectric constant with temperature is shown in figure 2. Maximum in dielectric constant is found to increase with increasing PZT up to 22 mole $\% \mathrm{PZ}$ (0.6-0.4) composition. $T_{c}$ increases with the increase of PZT. Variation of $T_{c}$ for different compositions are shown in table 1 . All compositions exhibit typical relaxor 
Table 1. Lattice parameters and dielectric data of modified PMN-PZT ceramics.

\begin{tabular}{lccrrrr}
\hline $\begin{array}{l}\text { Composition } \\
\text { PMN-PZT }\end{array}$ & Density & $\begin{array}{c}\text { Lattice } \\
\text { constant }\end{array}$ & $\varepsilon_{R T}$ & $T_{\mathbf{c}}\left({ }^{\circ} \mathrm{C}\right)$ & Tan $\delta$ & $\varepsilon_{\max }$ \\
\hline $0.4-0.6$ & 7.55 & 4.041 & 633 & 222 & 0.06 & 16375 \\
$0.5-0.5$ & 7.56 & 4.08 & 1586 & 210 & 0.08 & 15965 \\
$0.6-0.4$ & 7.51 & 4.083 & 1096 & 157 & 0.03 & 20753 \\
$0.6-0.4(0.01 \mathrm{La})$ & 7.53 & 4.074 & 4260 & 102 & 0.06 & 12637 \\
$0.7-0.3$ & 7.55 & 4.085 & 2616 & 118 & 0.09 & 10580 \\
$0.7-0.3(0.01 \mathrm{La})$ & 7.58 & 4.056 & 7243 & 60 & 0.09 & 9380 \\
$0.8-0.2$ & 7.60 & 4.055 & 2181 & 78 & 0.03 & 3573 \\
\hline
\end{tabular}
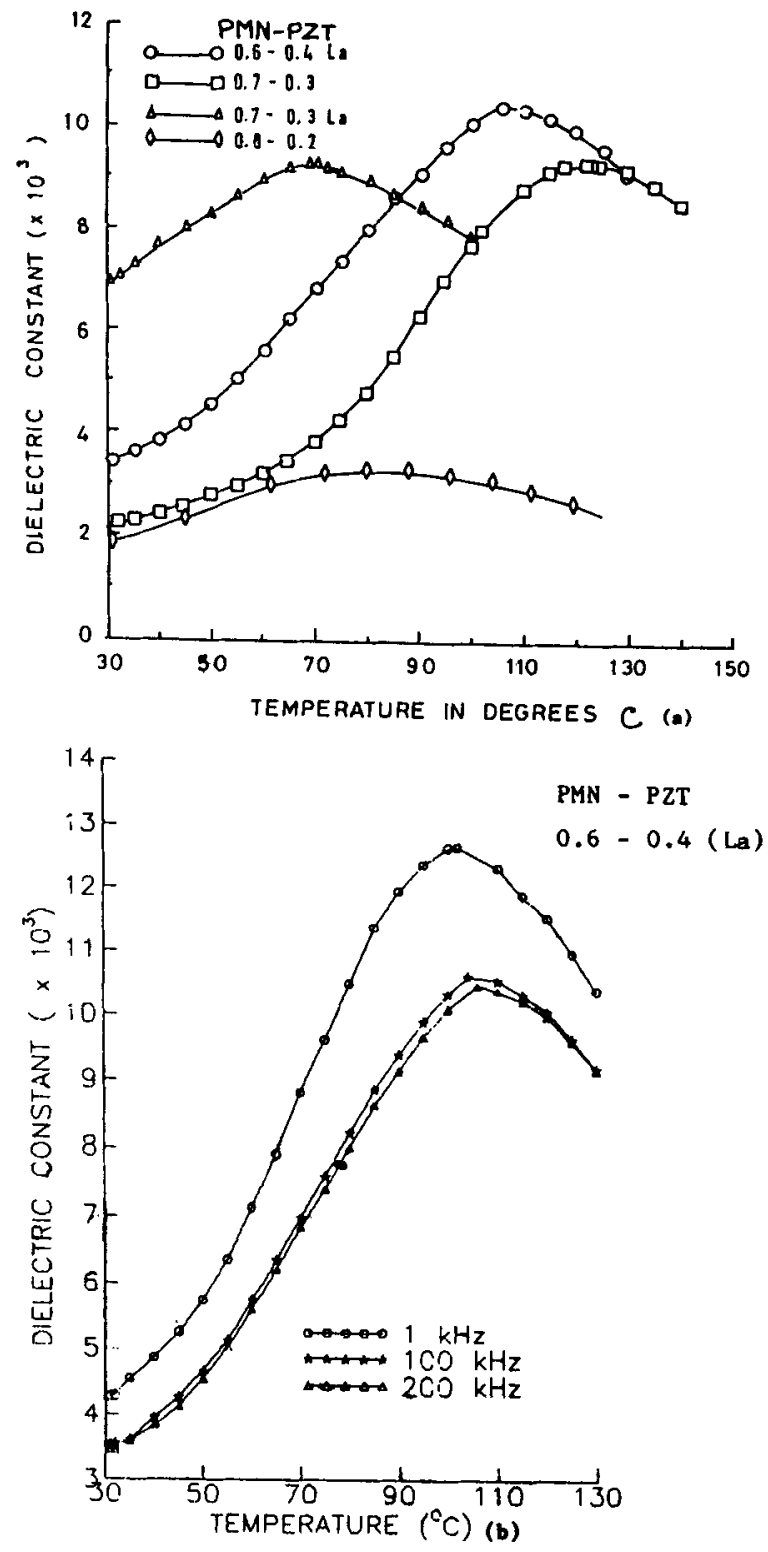

Figure 3. a-b. 


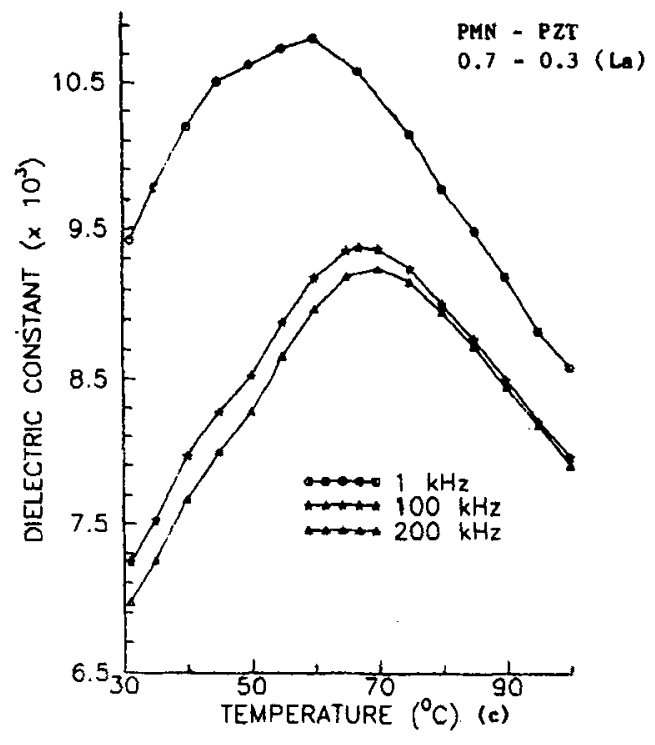

Figure 3. a-c. Relaxor behaviour of PMN-PZT compositions.

Table 2. Hysteresis data and piezoelectric properties of PMN-PZT ceramics at room temperature.

\begin{tabular}{|c|c|c|c|c|c|c|}
\hline PMN-PZT & $\underset{\left(\mu c / \mathrm{cm}^{2}\right)}{P}$ & $\underset{\left(\mu \mathrm{c} / \mathrm{cm}^{2}\right)}{P_{\mathrm{s}}}$ & $\begin{array}{c}E_{\mathrm{c}} \\
(\mathrm{K} v / \mathrm{cm})\end{array}$ & $K_{p}$ & $K_{t}$ & $\begin{array}{c}d_{33} \\
\left(\mathrm{Pc}^{\prime} / \mathrm{N}\right)\end{array}$ \\
\hline A & 13.63 & $18 \cdot 54$ & $2 \cdot 28$ & $26 \cdot 3$ & 10.5 & 116 \\
\hline B & $19-56$ & $25 \cdot 48$ & 3.14 & 38.2 & 11.9 & 262 \\
\hline $\mathrm{C}$ & $30 \cdot 48$ & 43.55 & 1.81 & $28 \cdot 6$ & $14 \cdot 1$ & 132 \\
\hline
\end{tabular}

Composition: A, 0.4 PMN-0.6 PZT; B, 0.5 PMN-0.5 PZT; C, 0.6 PMN-0.4 PZT.

behaviour as evidenced by decrease of dielectric maximum and shift of Curie temperature upwards with increasing frequency as shown in figure 3. Lanthanum doping of $1 \mathrm{~mole} \%$ in selected composition leads to a remarkable increase in room temperature dielectric constant. Dielectric constant variation with temperature is nearly flat for $0-8-0.2$ composition. This composition may have application in multilayer capacitors. This result is supported by the fact that already more than ten PMN based capacitors have been patented (Goodman et al 1991). It is significant that one of them is PMN-PLZT. For standard MLC (Takahashi and Ochi 1992) room temperature capacitance is $1, \mu \mathrm{F}$ and change in capacitance for $10^{\circ} \mathrm{C}$ is $380 \mathrm{PF}$. In our work for $0.8-0.2 \mathrm{PMN}-\mathrm{PZT}$ the change in capacitance for $10^{\circ} \mathrm{C}$ is $383 \mathrm{PF}$ and room temperature capacitance is $1838 \mathrm{PF}$.

Piezoelectric measurements were done on 0.4-0.6, 0.5-0.5 and 0.6-0.4 PMN-PZT compositions. Piezoelectric properties and hysteresis behaviour are given in table $2 . K_{p}$ value of 0.38 obtained in 0.5-0.5 composition is slightly lower than the $K_{\mathrm{p}}$ value of 0.46 in PZT (55/45) (Landolt-Bornstein 1981). Low $E_{\mathrm{c}}$ values in these compositions indicate dominance of rhombohedral structure. While in PMN-PZT (Kim 1989) ceramics maximum remanent polarization is of the order of $20 \mu \mathrm{c} / \mathrm{cm}^{2}$ at approximately 
$-110^{\circ} \mathrm{C}, P_{\mathrm{r}}$ value of $30 \mu \mathrm{c} / \mathrm{cm}^{2}$ obtained in $0 \cdot 6-0.4 \mathrm{PMN}-\mathrm{PZT}$ composition in the present work is high.

PZT (55/45) (Landolt-Bornstein 1981) exhibits a $d_{33}$ value of $150 \times 10^{-12} \mathrm{CN}^{-1}$. In PMN (Nomura and Uchino 1982) electric field induced $d_{33}$ is $240 \times 10^{-12} \mathrm{CN}^{-1}$ with an electric field of $12 \times 10^{5} \mathrm{~V} / \mathrm{m}$. The $d_{33}$ value of $262 \times 10^{-12} \mathrm{CN}^{-1}$ obtained in 0.6-0.4 PMN-PZT composition is certainly greater than either of the end members. Hence it can be concluded that the $d_{33}$ value is enhanced in $0.5-0.5 \mathrm{PMN}-\mathrm{PZT}$ when compared with either of the end members.

\section{Conclusions}

(i) X-ray diffraction results indicate rhombohedral structure in 0.5-0.5, 0.7-0.3 and $0.8-0.2$ PMN-PZT compositions. It is found that lanthanum doping leads to ordering of the structure.

(ii) Variation of dielectric constant with temperature at different frequencies exhibits relaxor characteristics. $0 \cdot 8-0 \cdot 2$ shows flat dielectric response with temperature indicating applications in multilayer capacitors.

(iii) Piezoelectric measurements indicate high $d_{33}$ value in $0.5-0.5 \mathrm{PMN}-\mathrm{PZT}$ composition. Low $E_{\mathrm{c}}$ values are obtained in all compositions consistent with rhombohedral structure.

\section{References}

Goodman G, Buchanan R C and Reynolds T G 1991 in Ceramic materials for electronics (ed.) R C Buchanan (New York: Marcel Dekker) p. 100

Kim N, Huebner W, Jang S J and Shrout T R 1989 Ferroelectrics 93341

Landolt-Bornstein Tables 1981 Ferroelectric and related substances (New York: Springer-Verlag) Vol. 16

Nomura S and Uchino K 1982 Ferroelectrics 41117

Ouchi H, Nagano K and Hayakawa S $1965 \mathrm{~J}$. Am. Ceram. Soc. 48630

Sinha J 1965 J. Sci. Instrum. 42696

Swartz S L and Shrout T R 1982 Mater. Res. Bull. 171245

Takahashi S and Ochi A 1992 in Electronic ceramic materials (ed.) J Nowotny (USA: Trans Tech Publications) p. 267 